\title{
ДЖУЛЬЕТА ОТТАВИАНО
}

\section{Г. ШПЕТ: ПУТЬ ОТ ФЕНОМЕНОЛОГИИ К ГЕРМЕНЕВТИКЕ}

\section{G. SHPET: A WAY FROM PHENOMENOLOGY TO HERMENEUTICS}

This article examines the analysis of themes relevants to Husserl's phenomenology, which are pre-sent in Appearance and Sense by Gustav Shpet: the relation between sense and comprehension and between noesis and noema. Shpet emphasizes the hermeneutical theme regarding «comprehension» as a resolutive dimension to solve aspects not clarified by Husserl. The Shpet's critical enquiry, in the course of his subsequent observation, gets to an hermeneutical logic. Shpet identifies the centrality of language as a form of thinking, through the recovery of the Humboldt's meaning of the «inner form».

Keywords: Gustav Shpet, Sense and Comprehension, noema, noesis, hermeneutical logic, the inner form, philosophy of culture.

В статье рассматриваются некоторые важные темы феноменологии Гуссерля, к которым Густав Шпет обращается в «Явлении и смысле», а именно: связь смысла и понимания, ноэзы и ноэмы. Шпет делает акцент на герменевтической составляющей «понимания», что предстает у него как «новое измерение» тех аспектов, которые оказались недостаточно прояснены Гуссерлем. Дальнейшее развитие этих тем приводит Шпета к «герменевтической логике». Опираясь на гумбольдтовское понятие «внутренней формы», Шпет делает центром своих исканий язык как процесс оформления мысли.

Ключевые слова: Густав Шпет, понимание и смысл, ноэма, ноэзис, герменевтическая логика, внутренняя форма слова, философия культуры.

\section{ПОНИМАНИЕ И СМЫСЛ}

Понимание и смысл являются сквозными темами, объединяющими все научное творчество Шпета, они рассматриваются им применительно к философии, логике, эстетике и лингвистике. И поскольку изложение своих мыслей Шпет всегда сопровождает обширным историческим экскурсом, его работы синтезируют также наследие европейской традиции во всех указанных областях. Для западных исследователей представляет большой интерес установление отправных точек шпетовской мысли, поскольку они позволят, с одной стороны, увидеть идейную преемственность взглядов русского философа по отношению к европейскому наследию, а с другой — выявить их своеобразие в предельно широком контексте, от античности до современных ему мыслителей.

(C) Д. ОттАвИАно, 2013 
Начнем наш анализ с первого произведения Шпета «Явление и смысл». Проблема понимания является одной из гуссерлевских тем, к рассмотрению которой Шпет обращается в двух последних главах своей работы. Однако прежде чем приступить к самому тексту, представляется уместным тезисно привести положения из работы А. Э. Савина, в которых он выявляет различия позиций Гуссерля и Шпета:

1. Шпет понимает غ̇лохи́ как путь к эйдетическому усмотрению; отрицание рядоположенности эйдетической и трансцендентальной редукции;

2. Шпет сосредотачивает свое внимание на ноэматическом в противоположность анализу ноэтического;

3. Шпет не признает трансцендентального «Я» в сфере феноменологического анализа и рассматривает «Я» как объект эйдетической интуиции. «Явление и смысл» представляет собой работу, в которой дается интерпретация и критика взглядов Гуссерля, предваряющая более откровенную критику идей немецкого мыслителя в работе «Сознание и его собственник».

Антипсихологизм, возвращение к самим вещам, эпохе, идея создания строгой основной науки позволяют отнести Шпета к феноменологическому направлению. Вместе с тем особое восприятие феноменологии и внимание к таким темам исследования, как разъяснение аспектов, относящихся к дотеоретической сфере, внимание к структуре ноэмы, стремление понять мир как ноэму и одновременно интерес к построению онтологии реального, все это сближает Шпета с Мюнхенской школой и Геттингенским кружком. ${ }^{1}$

Отличительная черта шпетовского восприятия феноменологии, как по мнению Савина, так и по мнению Хаардта ${ }^{2}$, состоит в том, что он основывается на «Логических исследованиях», в то время как феноменологический идеализм «Идей» вызывает у него критическое отношение.

Итак, «ноэма как смысл» - содержание последних двух глав «Явления и смысла». В предпоследней главе, Явление и действительность, Шпет замечает, что именно интенциональность является главной темой феноменологии и подтверждает свою мысль цитатой из «Идей І»: сущность феноменологии заключается в возможности «чистого» рассмотрения феномена и, поскольку она является учением об эйдетическом, то рассматривает не реальное явление, но явление трансцендентально редуцированное. ${ }^{3}$

Раскрыть структуру отношения ноэмы и ноэзы представляется Шпету существенно важным, чтобы прояснить отношение с реальностью, с опы-

1 Савин А. Э. Интерпретация и критика Г. Г. Шпетом философии Эд. Гуссерля // Шпет Г. Г. Comprehensio. Вторые Шпетовские чтения. Томск: Водолей, 1997. С. 26-27.

2 Haardt A. Gustav Shpet's Appearance and Sense and Phenomenology in Russia // Shpet G. Appearance and Sense: Kluwer Academic Publishers, Phenomenologica, 1991. P. XXIV-XXV.

3 Шnет Г. Г. Явление и смысл. М.: Гермес, 1914. С. 159. 
том. Шпет цитирует 98 параграф «Идей I», в котором Гуссерль говорит о способе бытия ноэмы, о формах ноэзы и ноэм: «Можно набрасывать всеобщеее и чистое учение о формах ноэм, учение, которому коррелятивно противостояло бы всеобщее и не менеее чистое учение о формах конкретных ноэтических пережсиваний с их гилетическими и специфически ноэтическими компонентами. Естественно, то и другое учение никоим образом не стали бы соотноситься друг с другом как зеркальные отражения, переходя друг в друга путем простой перемены индекса, скажем так, что мы любой ноэме $\mathrm{N}$ субституировали "сознание-чего" - сознание $\mathrm{N».}{ }^{4}$

Гуссерль продолжает, утверждая, с одной стороны, наличие параллелизма ноэзы и ноэмы, а с другой - особый характер этого параллелизма: ноэматический план представляет собой «поле единств, ноэтическое - поле “конституирующих" многообразий. Сознание же, “функционально" единящее многообразие и одновременно с тем конституирующее единство, на деле никогда не являет тождества там, где в ноэматическом корреляте дано тождество “предмета"». Необходимо видеть различие «между конкретными ноэтическими переживаниями, переживаниями вкупе с их гилетическими моментами и чистыми ноэзами как простыми комплексами ноэтических моментов. А далее мы должны точно так же соблюдать различие между полной ноэмой и, например, в случае восприятия, “являющимся предметом как таковым"». ${ }^{6}$

Гуссерль прекрасно понимает необходимость всеобъемлющего анализа параллелизма ноэмы и ноэзиса, представляющее собой сложное и многообразное явление, которое не ограничивается только сферой восприятия. С этой целью он рассматривает «полную ноэму» и «полную ноэзу», реактуализацию, эйдетические законы, определяющие ступенчатый характер переживаний, характеристики «веры», модификацию «нейтральности».

Шпет в главе Явление и действительность синтезирует, сопровождая краткими пояснениями и подтверждая цитатами, проблематику «Идей I», касающуюся ноэзо-ноэматических структур. При этом он делает акцент на специфике феноменологического подхода: «Феноменология использует совершенно особым образом те связи, которые устанавливаются между нею самой в решении проблемы “конституции" (“конститутивные феноменологии") и соответственно между онтологиями, как формальными, так в особенности и материальными. Феноменология здесь не “подчиняется" онтологиям и не получает из них “обоснования", она только пользуется он-

4 Гуссерль Э. Идеи к чистой феноменологии и феноменологической философии. М.: Академический проект, 2009. С. 316-317.

5 Там же. С. $317-318$.

6 Там же. С. 318. 
тологическими положениями и понятиями, как “руководящей нитью” для собственной цели, - как говорит Гуссерль, - онтологическое понятие или положение служит “индексом” для конститутивных связей сущности». ${ }^{7}$

Несколькими строками ниже Шпет приводит последний абзац «Идей I»: «Всестороннее, обращенное одинаково, как на ноэтические, так и на ноэматические слои сознания, решение конститутивных проблем явно было бы эквивалентно полной феноменологии разума во всех его формальных и материальных, а вместе с тем в его аномальных (негативно-разумных), равно как и его нормальных (позитивно-разумных) формациях. Но далее напрашивается, что такая полная феноменология разума совпала бы с феноменологией вообще, что систематическое выполнение всех описаний в сфере сознания, какие требуются общим титулом предметной конституции, должны были бы обнимать в себе все описания в сфере сознания вообще». ${ }^{8}$

Тот факт, что каждое переживание характеризуется интенциональностью, уже подчеркивалось Гуссерлем в V и VI разделах «Логических исследований». Ноэза - это «интенциональное морфе», направленность на предмет (восприятие, воспоминание, воображение), ноэма - это предмет, рассматриваемый сознанием в различных способах его бытия (воспринимаемый, воображаемый, данный в воспоминании), это объективный элемент опыта, который не является самим предметом.

Между данностью как ощущением и данностью как ноэмой, как указывает В. Коста, существует фундаментальная феноменологическая разница, поскольку ноэма и ноэза имеют разный статус, несомненность ноэмы не зависит от существования или несуществования воспринимаемого, и восприятие может осуществляться в отсутствие реального предмета. ${ }^{9}$

Анализ взаимоотношения ноэмы и ноэзы, по Шпету, должен разъяснить источник и способ перехода «от выражения к смыслу» и того, как «хромое» логическое выражение овладевает «слепым» значением. ${ }^{10}$

Ряд вопросов возникает по поводу интенционально-эйдетических связей предмета и сознания, о том, каким образом предмет обнаруживает свою разумность, о том, как предписываются эти правила, если нет «понимания действительности».

Шпет пишет: «Категория предмета в своей адекватной данности предписывает общее правило для всякого особого предмета, становящегося в многообразии конкретных переживаний, но как “явление” может предписывать “правила” для положения, если мы не знаем, подчиняется ли и как

Шnет Г. Г. Явление и смысл. С. 166.

Там же. С. $167-168$.

Costa V. Husserl. Carocci, 2009. P. 44-48.

10 Шnет Г. Г. Явление и смысл. С. 168-169. 
оно само разумному правилу? А что дают нам эти “правила” без уразумения действительности?

Они дают, конечно, очень много: они составляют основание не только методологии, как формального учения, но и “натурфилософии”, “философии духа”, “философии истории” и т. д., однако и здесь нельзя усмотреть, как же простая возможность может стать действительностью?» ${ }^{11}$

Шпет таким образом отсылает непосредственно к $\S 142$ «Идей», в котором Гуссель утверждает: «Любая предметная категория (и, соответственно, любой регион и любая категория в нашем суженном, отчетливом смысле) это всеобщая сущность, какую и саму можно в принципе доводить до адекватной данности. В своей же адекватной данности категория предписывает усмотримое генеральное правило - предписывает любому особенному, осознаваемому в многообразиях конкретных переживаний предмету (переживания здесь, естественно, берутся не как индивидуальные единичности, но как сущности, как конкретности низшего вида). Предметная категория предписывает правило для того способа, каким подчиненный ей предмет можно было бы, по смыслу и способу данности, приводить к полной определенности, к адекватной первозданной данности, какими отъединенными или же непрерывно протекающими взаимосвязями сознания, каким конкретным наделением сущностью этих взаимосвязей». ${ }^{12}$

Шпет констатирует, что представление о предмете в его адекватной данности отсылает к идее Канта (ср. «Идеи I», §143), когда у Гуссерля речь заходит об адекватной данности явления, о полной предначертанной данности, о системе, определенной по своему сущностному типу, в пределах которой происходит бесконечный процесс непрерывного явления и которая является «континуумом явлений». Шпет, всегда критически относившийся к кантианству, подчеркивает, что для Гуссерля идея «адекватной данности» не может быть только регулятивной, как для Канта, и что само понятие максимума вызывает ряд вопросов:

«Но ведь весь вопрос в том и состоит, как мы усматриваем этот “максимум", как мы усматриваем, что мы его еще не выполнили, как мы усматриваем, что проблема есть? Должны ли мы довольствоваться утверждением Канта, что идеи “даны природой самого разума”? Или перед нами по-прежнему остается вопрос: как есть сам разум? Гуссерль сам говорит: “Идея по существу мотивированной бесконечности не есть сама бесконечность; усмотрение того, что эта бесконечность принципиально не может быть дана, не исключает, а скорее требует усматриваемой данности (идеи этой бесконеч-

11 Там же. С. 171.

12 Гуссерль Э. Идеи к чистой феноменологии и феноменологической философии. С. 443. 
ности)". Ну, так вопрос ведь именно в том, как мы усматриваем эту идею, как она есть?» ${ }^{13}$

Гуссерль различает «заключенное явление» (термин Шпета) и априорный «континуум явлений», что подразумевает существование различных видов данности. Второй вид данности не может рассматриваться как первичная данность. Напротив, признание адекватности только за этим видом данности составляет принципиальное отрицание первичной адекватной данности. «Заключенное явление», распростертое в «бесконечный ряд», тем самым перестает быть таковым. Далее Шпет утверждает, что имманентное восприятие тоже может быть адекватным и что может существовать возможность адекватной данности явления, которая дает предмет не только в его смысле, но также и в его потенциальном состоянии, «готовности быты». ${ }^{14}$

Все нити смысла связываются, по утверждению Шпета, в этом центральном узле: может быть понят не только смысл явления, но также тот X, носитель смысла, который мы в состоянии постичь и который делает индивидуальное индивидуальным и конкретное конкретным, притом в их полной разумной мотивированности.

Затем Шпет обращается к вопросу о «региональных онтологиях», которые приобретают ведущую роль для решения «конститутивных проблем». Если феноменология совпадает с феноменологией разума, отсюда следует, что главными ее проблемами становятся «разум», «уразумение», «действительность». ${ }^{15}$ Шпет подчеркивает, что сущность феноменологии составляет интенциональность, которая, по утверждению Гуссерля, является ее отправным пунктом. ${ }^{16}$

В заключительной главе книги, озаглавленной Смысл и уразумение, Шпет опять-таки точно соблюдает порядок изложения Гуссерля в «Идеях I». В этой главе Шпет намеревается предложить «ответы» на вопросы, которые не удалось решить Гуссерлю. Так, недостаточно проясненными ему представляются отношения между ноэмой и ощущениями, а также то, каким образом происходит легитимация придания и усмотрения смысла. В более детальном объяснении нуждается различие между интуицией интеллектуальной и эмпирической. Он подчеркивает важность феноменологической редукции, которая не уничтожает данного в опытной интуиции, но видит его

13 Шnет Г. Г. Явление и смысл. С. 172-173. Шпет цитирует последний абзац § 143 «Идей І». 14 Там же. С. 174.

15 Там же. С. 175.

16 Ср.: «Проблемная рубрика, объемлющая всю феноменологию в целом, называется интенциональностью. Эта рубрика выражает основополагающее свойство сознания, - все феноменологические проблемы, даже и гилетические, включаются в нее. Тем самым феноменология начинает с проблем интенциональности...» (Гуссерль Э. Указ. соч. С. 452.) 
другим зрением; сама же сущность усматриваемого остается неизменной при переходе от одной установки к другой. ${ }^{17}$

Затем он переходит к теме о смысле как об «абстрактной форме» и задается вопросом, каким образом «форма» может являться «смыслом», «содержанием» предмета или ноэмы? При «теоретическом» ответе на этот вопрос необходимо вернуться к учению Аристотеля, чтобы затем проделать путь до Лейбница. Шпет, пользуясь примером Аристотеля, говорит о секире, чей «внутренний смысл» заключается в «рубить», и утверждает, что в понятии секиры присутствует не только слой чистых определений «как», но также и «внутрениий смысл», заключающийся в том, что секира «рубит». «Рубить» - это «душа», или «энтелехия», секиры.

Сущность ноэмы понимается Шпетом как «энтелехия», которая закрепляет предмет в его конкретности и, в свою очередь, представляет ядро ноэмы.

Лишь на заключительных страницах последней главы «Явления и смысла» после самого настоящего «критического комментария» к «Идеям», Шпет предлагает свое решение гуссерлевских «дилемм». Отдельные замечания о необходимости «герменевтического подхода» к феноменологии, можно обнаружить уже во введении и в первой главе, посвященной интуиции. Подобные утверждения имеются также в заключительной части, которая даже по стилю изложения отличается от остального текста: это проникнутая пафосом почти художественная проза. Цитаты, которыми Шпет заканчивает главу, затрагивают темы, которыми он будет заниматься в последующих работах, посвященных вопросам герменевтики, эстетики и философии культуры; в Заключении философ вновь подчеркивает примат философии в объяснении мира по отношению к сциентизму. Роли понимания Шпет посвящает следующий фрагмент, показательный для его философской позиции: «К сущности самого сознания принадлежит не только усматривать, но и понимать, уразумевать усмотренное. И это “уразумение" не есть только умозаключение, как не есть оно только и репрезентативная функция вообще, но и презентативная. Она, действительно, окрыляет предметы, одушевляет их, и мы, действительно, можем говорить об особой группе предметов, к сущности которых относится быть уразумеваемыми. Феноменологический анализ охватывает собою всякое психологическое разделение и держит под собою это чудесное единение индивидов, как один из “актов", наряду со множеством других, для него нет “одиночных тюрем” <...>. Абсолютное сочииальное одиночество, “одиночная камера”, есть удел не индивида как такого, а только сумасшедшего; утерять способность интеллигибельной интуиции, уразумения, даже при полном совер-

17 Там же. С. 187-188. 
шенстве интуиции опытной и идеальной, - значит сойти с ума, - единственный путь выхода из социального единения». ${ }^{18}$

\section{ГЕРМЕНЕВТИЧЕСКАЯ ЛОГИКА}

Определение «герменевтическая логика» встречается у Шпета, как указывает Ф. Роди, в книге «Герменевтика и ее проблемы», а именно, в главе, посвященной Шлейермахеру. В этой работе, носящей историко-философский характер, Шпет не только прослеживает историю герменевтики от античности до современной ему эпохи, но и стремится осуществить синтез логико-семиотического и герменевтического подходов - последний из которых объединяет филологическую и теологическую традицию, — чтобы пересмотреть задачи логики, которые решались бы в «герменевтическом» аспекте. «Шпет стремился к “радикальному пересмотру задач логики”, который стал бы результатом “решения герменевтических проблем”: но о каких же проблемах шла речь? Вкратце их можно сформулировать так: с одной стороны, вопрос о предмете понимания и интерпретации, а с другой, вопрос об особом характере акта понимания. В терминах семиотики это вопрос об особом характере словесного знака, передаваемого из поколения в поколение, и проблема адекватности его понимания». ${ }^{19}$

О преемственности «Герменевтики и ее проблем», как и всех последующих научных трудов Шпета, по отношению к «Явлению и смыслу» свидетельствует сосредоточенность автора на проблемах акта понимания и на онтологии предмета понимания. Анализируя отношения философии и герменевтики, Шпет замечает, что Шлейермахеру не удалось увидеть реальное различие между пониманием (актом) и интерпретацией: «Истолкование начинается как раз с того момента, где кончается понимание, где непосредственного понимания $<. .>$ недостаточно, $<. .>$ источником интерпретации, другими словами, является именно не-понимание. <..> Всю разницу <..> он видит не в том, что, с одной стороны, встречаются с чем-то “чужим”, а с другой - с чем-то “своим”, как и не в разнице между речью письменной и устной, а исключительно только в том, что одно хотят понять точно, а другое - нет. Выходит, как будто вся разница между пониманием и интерпретацией — в степени точности». ${ }^{20}$

Шпет считает, что герменевтика связана с мыслью, речь — это акт внешний по отношению к мышлению, отсюда следует, что «герменевтика долж-

18 Там же. C. 207-208.

19 Rodi F. Conoscenza del conosciuto. Milano, 1996. Р. 148-149. См. русский перевод И. Чубарова: $Р о д и ~ Ф$. Герменевтическая логика в феноменологической перспективе: Густав Шпет // Логос. 1996. № 7. С. 41-46.

20 Шnет Г. Мысль и слово. М.: РОССПЭН, 2005. С. 318-319. 
на быть философской» ${ }^{21}$ Шпет указывает на взаимосвязь, существующую между герменевтикой и риторикой: «Они параллельны в той же степени, в какой параллельны язык и понимание, каждый акт понимания - это обращенный акт речи» ${ }^{22} \mathrm{~B}$ самом акте понимания он подчеркивает двусторонность, так как для его осуществления требуется присутствие говорящего, который создает текст, и слушающего, который его воспринимает. Акт понимания требует взаимодействия двух компонентов, причем Шпет подчеркивает, что непосредственное понимание не только предшествует какой бы то ни было логической или грамматический формулировке понимающего, но также и то, что сам говорящий облекает свое высказывание в логические и грамматические формы, поскольку он уже «понимает, что намеревается сказать». ${ }^{23}$

Представляется очевидным, что Шпет различает акт «схватывания» смысла и акт, во время которого смысл облекается в слова. Как замечает Роди, цитируя Дильтея, понимание есть не только «процесс, противоположный переживанию», оно представляет собой акт придания смысла, который происходит как в говорящем, так и в слушающем, и при котором обе стороны нуждаются в языковом выражении. ${ }^{24}$

Если в основе герменевтики лежит понимание, логика, по Шпету, играет менее важную роль, и об этом он пишет в заключительной главе «Явления и смысла». Логика занимается формальной стороной уже сформулированного смысла, в то время как герменевтике логика не нужна. Логика должна стать «специально герменевтической логикой», «логикой интерпретации». Однако дальше этого программного заявления Шпет не идет.

Размышления о языке, начатые в «Явлении и смысле» и продолженные в «Герменевтике и ее проблемах», находят свое завершающее выражение в книге «Внутренняя форма слова». А. Митюшин в статье «Сфера языка в логической концепции Шпета» отмечает, что Шпет разрабатывает собственную теорию понятия, определяя свой философский метод как «диалектику, интерпретирующую научные понятия». Слово для Шпета представляет собой «principium cognoscendi»: он называет слово «источником познания〉 в буквальном смысле, подразумевая под этим то первоначало, от которого отправляется наше высказывание. Общий «логический слой» предметных значений раскрывается в мышлении через внутреннюю форму языковых значений. ${ }^{25}$

21 Там же. С. 321.

22 Там же. С. 322.

23 Rodi F. Op. cit. P. 152.

24 Там же.

25 Mitjušin A. La sfera del linguaggio nella concezione logica di Špet // Slavia. 1994. № 4. P. 23. 
Рассматривая тему логической формы языка, Шпет говорит об ограничительном характере традиционной логики, которая превратилась в «логику вещей», классифицирующую характеристики предметов. ${ }^{26}$

Значение приходит к нам, утверждает Шпет, в форме понятия, и доходят до нас не только значения, но и их понимание. Понятие никогда не отрывается от понимания. Шпет стремится показать односторонность логиков, для которых проблема смысла отходит на второй план, вместе с тем, сосредоточенность логики на смысловом аспекте может представлять опасность для самостоятельности формальной логики как науки. «Логические формы должны быть вскрыты, как в их относительной автономности, так и в их взаимоотношениях с предметной мыслью. Формалистическая логика, основывающаяся на чистых отношениях объема, при всем своем “формализме”, есть все же незаконное дитя онтологической логики. Логика идет новым курсом, где в нее проникает сознание роли самих “значений” в образовании форм мысли, где логика, иными словами, становится семантической», пишет он во фрагменте «Язык и смысл». ${ }^{27}$ Динамизм логических форм, представляет собой динамизм самого мышления. Первостепенная важность понимания, на котором основывается интерпретация, превращает герменевтику в науку первостепенной важности по сравнению с логикой, и сама логика должна развиться в «герменевтическую».

\section{ТЕМЫ ГУМБОЛЬДТА В РАБОТЕ «ВНУТРЕННЯЯ ФОРМА СЛОВА»}

Подзаголовок книги свидетельствует о том, что Шпет, размышляя о вопросах языка, подчеркивает преемственность своих идей по отношению к Гумбольдту: для Шпета работы Гумбольдта являются основой современной ему лингвистики и философии языка. Традиции Гумбольдта важны не только для науки о языке, они тесно связаны с судьбами философских исканий в целом. Во вступлении Шпет указывает, что предметом его рефлексии являются темы основного труда Гумбольдта «Введение к исследованию яванских языков», некоторые идеи которого вошли в русский научный оборот благодаря Потебне.

Для лингвистических идей Гумбольдта характерно то, что язык становится центром философского исследования. Из простого средства общения он превращается в наиболее важный инструмент связи между человеком и миром. Шпет следует за Гумбольдтом в признании того, что язык есть «орган внутреннего бытия» ${ }^{28}$ и играет главную роль в эволюции духа народа. Он

26 Шnет Г. Г. Язык и смысл. С. 33.

27 Там же.

28 Шnет Г. Г. Внутренняя форма слова. М.: Едиториал УРСС, 2003. С. 11 
также подхватывает утверждение, что язык есть непрерывное становление, он не является конечным «продуктом», но «вечно повторяющейся работой духа». ${ }^{29}$ Пользуясь терминами Гумбольдта, Шпет подчеркивает, что язык по своей сущности преходящ: он не произведение, но деятельность, посредством которой в звуках выражается мысль. Реализация языка происходит в речи, а не в разрозненных словах или правилах. Язык, следовательно, это образующий орган мысли, интеллектуальная, духовная деятельность, протекающая во внутреннем мире и, благодаря звучащему слову, получающая внешнее выражение и воспринимаемая чувствами. Шпет основывается на этих положениях Гумбольдта, определяя внутреннюю форму языка как духовное единство, объединяющее отдельные материальные элементы.

В первых главах «Внутренней формы слова» мы вновь встречаем тему, заключающую «Явление и смысл»: понимание и взаимное понимание. Она, в свою очередь, входит в круг гумбольдтовских тем. «Язык возникает из первичной потребности в свободной человеческой общительности», - пишет Шпет и приводит слова Гумбольдта, определяя человека как «поющее животное», «связывающее со звуками мысль». ${ }^{30}$ Язык в целом одновременно является процессом порождения мысли и развитием человеческих способностей под влиянием среды, однако было бы неверно определять его как развитие инстинктов, ограниченных физиологиией, так как язык рождается во внутреннем мире человека, из внутренних его сил. Шпет указывает, что у языка существуют два конститутивных принципа: внутреннее чувство языка и звук. Сущность языка нельзя сводить к внешней структуре, грамматической конструкции, истинные его характеристики обнаруживаются в общем ходе развития самих языков, — язык можно уподобить кристаллу, формирующемуся постепенно, но закономерно.

Шпет считает, что, рассматривая идеи Гумбольдта в области философии языка, истории философии и эстетики, нельзя не упомянуть о его связях с Гердером и Кантом. Проблемы языка, трактуемые Гердером «по вдохновению и чутью», ставятся Гумбольдтом на научную и философскую основу. От Гердера наследуется им круг проблем, таких как происхождение и генеалогия языка, классификация языков и, наконец, роль языка в развитии духа. Что касается понятийного аппарата, здесь Гумбольдт обращается к философским и психологическим терминам Канта, но использует их только как эвристический инструмент. Кантианство воспринимается им через призму поэзии и эстетики немецких романтиков, Гете и Шеллинга.

29 Там же. С. 13.

30 Там же. С. 17. Ср.: Гумбольдm B. «О различии строения человеческих языков и его влиянии на духовное развитие человечества». 
Тот факт, что Гумбольдт не выработал собственных понятий, не позволило понять важность его вклада в науку, между тем, мысль его достигла таких высот, что его можно было бы поставить рядом с Гегелем. «Порою прямо кажется, что философия языка Гумбольдта призвана завершить собою систему философии Гегеля, <...> сделаться центральною проблемою философии духа, реализующего в языке все другие конкретные проблемы философии». ${ }^{31}$ Благодаря Гумбольдту язык может быть определен как «духовная деятельность», «внутренняя деятельность Духа». Но Гумбольдт идет дальше Гегеля, говоря, что «язык есть такая форма воплощения духа и идеи, без существования которой для нас не было бы ни духа, ни идеи». ${ }^{32}$

Определив язык с точки зрения формы, он переходит к анализу понятия фонетической формы, и именно в этом контексте появляется термин «внутренняя форма». Взяв за основу понятие звуковой формы, он устанавливает конститутивный и руководящий принцип различия языков и пользуется им, чтобы выделить типы языков и создать их классификацию. Однако, звуковое разнообразие, как замечает сам Гумбольдт, представляет собой прежде всего «содержание»: каким образом оно способно образовать формальное единство и стать конститутивным принципом? По аналогии с кантовскими формами пространства и времени Гумбольдт создает понятие «чистого артикуляционного чувства», а затем и отдельного артикуляционного звука. Артикуляционное чувство, замечает Шпет, не является простой способностью артикуляции, присущей человеку физиологически, но принципиальным свойством языка в качестве орудия мысли. Гумбольдтовская идея артикуляционного чувства уже содержит в себе критику теории языка как животного крика, а также любой психологической теории, основанной на ассоциациях и аналогиях.

Вводя понятие «внутренней формы», Гумбольдт подчеркивает, что в языке все представляет собой синтез, в данном случае, речь идет об объединии не двух абстрактных явлений, но двух элементов конкретной структуры, двух членов отношения: мысли и чистого звука.

Шпет, переходя к анализу понятия внутренней формы, бегло останавливается на истории данного термина и его интерпретации и вкратце характеризует два основных направления в его понимании: традицию ШтейнталяМарти и традицию, идущую от Гете.

Понимание внутренней формы у Гете с терминологической точки зрения представляется Шпету «наивным», оно являет собой род метафоры, служащей для обозначения энтелехии, «жизненной силы» произведения, понимаемого как «организм».

31 Там же. С. 33.

32 Там же. 
Разница между употреблением этого термина у Гете и у Гумбольдта состоит в том, что последний применяет его к языку, что ведет к конкретизации понятия: от «метафорической расплывчатости и иррациональности» Гумбольдт идет в направлении «строгости и рациональности». ${ }^{33}$ Впервые мы встречаем сам термин в эстетике Плотина, Фичино переводит его как «intrinseca forma», затем мы находим его у Дж. Бруно («Della causa, Principio et uno»), который, в свою очередь, испытывает влияние Плотина. Связующим звеном между плотиновской традицией эстетики Возрождения и немецким идеализмом, пишет Шпет, является английский платонизм, в частности, Шефтсбери, который также разрабатывает понятие внутренней формы.

У Гумбольдта этот термин появляется впервые, когда, анализируя «Германа и Доротею», он говорит о поэзии как искусстве слова, а затем развивает мысль, что язык - человеческий орган, а искусство - зеркало окружающего его мира. В поэтическом языке воображение и разум, индивидуальное и общее, внешняя и внутреняя форма не противоречат друг другу и не взаимоуничтожаются: их можно разделить только в абстракции, они нуждаются не в конечном синтезе, но в изначальном признании единства структуры. Остается открытым вопрос, можно ли говорить о внутренней форме языка по аналогии с искусством: либо язык как таковой является искусством, либо он некое явление, включающее в себя поэзию как отдельный элемент. По этому поводу Шпет отсылает к Кроче и Фосслеру.

Гумбольдт различает язык и поэзию, лингвистику и эстетику, но видит в них сходство, в основе которого лежит внутренняя форма языка, с одной стороны, и внутренняя поэтическая форма - с другой: «языковая», как и в первом случае, но «особая», модифицированная по сравнению с первой. Под «языковой формой» понимаются не часть языковой структуры и не отдельные языковые элементы, но язык как органическое целое, и, в этом смысле, «текучее» и «преходящее», «постоянная работа духа» по выражению мысли, осуществляющаяся «постоянным и единообразным способом». ${ }^{34}$ Однако, каким же образом объединяются звуковая форма и чисто мыслительное содержание? Шпет указывает, что если «звук» понимается как «членораздельный звук», то в этом превращении мы «открываем готовую интенцию быть выражением мыслительного содержания. <..> Само оно, мыслительное или смысловое содержание, оснащенное оформленным звуковым содержанием, в свою очередь, раскрывает свою интенцию объективного осмысления, т. е. осмысления, направленного на предельный предмет, разбрасывающийся, раздробляющийся, расплескивающийся в многообразии вещей, процессов и отношений так называемого “окружающего нас мира" $<\ldots>\gg .{ }^{35}$

\footnotetext{
33 Там же. С. 54.

34 Там же. С. 60-61.

35 Там же. С. 65
} 
Шпет таким образом демонстрирует, что проблема внутренней формы разрешена Гумбольдтом не полностью. В заключении третьей главы своей работы он резюмирует основные положения, касающиеся рассматриваемого им вопроса, и делает следующие выводы: внутренняя форма не есть чувственно-данная звуковая форма, это и не форма самого мышления, как не является она и формой предмета. Она пользуется звуковой формой для обозначения предметов и связи мыслей, «и при том, она пользуется внешнею формою для выражения любой модификации мыслимого предметного содержания, называемого в таком случае смыслом, настолько необходимо, что выражение и смысл, в конкретной реальности своего языкового бытия, составляют не только неразрывное структурное единство, но и в себе тожественное sui generis бытие (социально-культурного типа)». ${ }^{36}$

В сноске Шпет уточняет, что существует также внеязыковое сознание, «содержание бытия и переживаний за пределами языка». ${ }^{37}$ Последнее замечание подводит итог пути, который он прошел за все эти годы, который от «Явления и смысла» пролегает через диссертацию «Проблемы современной эстетики» и ведет к работе о Гумбольдте, а также к «Введению в этническую психологию», которое публикуется в том же 1927 году. Его искания устремляются в русло «философии культуры» и содержат размышления теоретического характера, которые принадлежат к высшим достижениям русской философской традиции.

\section{Автор}

ОТТАВИАНО ДжульЕТтА - Доктор философии, Университет Roma Tre, член совета Римского философского общества.

OTTAVIANO GiulieTta — Doctor, Professor, University Roma Tre, Department of Philosophy. Member of the Philosophical Society of Rome.

E-mail: giulietta.ottaviano@alice.it

\footnotetext{
36 Там же. С. 67.
}

37 Там же. С. 66. 